\title{
PENINGKATAN KEMAMPUAN MANAJEMEN DALAM PENGELOLAAN ELEKTRONIK KOMPLAIN LAYANAN LABORATORIUM UNIVERSITAS NURUL JADID
}

\author{
M. Fadhilur Rahman', M. Syafiih ${ }^{2}$, Zidan Abdallah Maulana Rahman³, \\ Imam Mawardi ${ }^{4}$, Ahmad Romadhani ${ }^{5}$, Taufiqur Rahman ${ }^{6}$
}

\author{
Universitas Nurul Jadid, Indonesia ${ }^{1}$ \\ Email:fadilurrahman88@gmail.com \\ Universitas Nurul Jadid, Indonesia ${ }^{2}$ \\ Email:m.syafiio1@gmail.com \\ Universitas Nurul Jadid, Indonesia ${ }^{3}$ \\ Email: zidanamro8@gmail.com \\ Universitas Nurul Jadid, Indonesia ${ }^{4}$ \\ Email: rizkisironaldo@gmail.com \\ Universitas Nurul Jadid, Indonesia ${ }^{5}$ \\ Email:ahmadromadhani181@gmail.com \\ Universitas Nurul Jadid, Indonesia ${ }^{6}$ \\ Email:opew.st12@gmail.com
}

\begin{abstract}
Abstrak
Laboratorium Komputer Universitas Nurul Jadidi menjadi tanggung jawab penuh Fakultas Teknik, pemanfaatan layanan laboratorium bagi mahasiswa teknik dan diluar Fakultas Teknik yang membutuhkan praktikum komputer. Penggunaan laboratorium diatur sesuai jadwal roster kuliah yang telah ditetapkan diawal perkuliahan pada setiap semesternya, sedangkan penggunaan ekstra akan disesuaikan diluar jadwal kuliah. Permasalahan yang terjadi adalah manajemen akan sulit menentukan jadwal tepat pagi pengguna laboratorium. Solusinya perlu adanya aplikasi yang mengatur penggunaaan serta kuluhan dari mahasiswa dan dosen, aplikasi tersebut akan mengakomodir semua kebutuhan dan keluhan yang ada di laboratorium komputer Fakultas Teknik. Agar manajemen paham menggunakan aplikasi perlu adanya pelatihan tujuannya agar mudah memahami penggunaan aplikasi e-komplain. Metode yang digunakan adalah Longitudinal Method merupakan metode untuk menentukan dan mengukur data secara berulang untuk satu atau beberapa variable. Hasilnya adalah aplikasi e-komplain yang sudah siap digunakan oleh Fakultas Teknik Universitas Nurul Jadid.
\end{abstract}

Kata Kunci: Peningkatan, Kemampuan, E-Komplain, Layanan, Laboratorium.

\section{Abstract}

The Computer Laboratory of Nurul Jadidi University is the full responsibility of the Faculty of Engineering, utilizing laboratory services for engineering students and outside the Faculty of Engineering who need computer practicum. The use of the laboratory is arranged according to the lecture roster schedule that has been set at the beginning of the lecture in each semester, while the extra use will be adjusted outside the class schedule. The problem that occurs is that management will find it difficult to determine the exact schedule for laboratory users in the morning. The solution is to have an application that regulates the use and appreciation of students and lecturers, the application will accommodate all the needs and complaints in the computer laboratory of the Faculty of Engineering. In order for management to understand using the application, training is needed to make it easier to understand the use of the e-complaint application. The method used is the Longitudinal Method, which is a method for determining and measuring data repeatedly for one or several variables. The result is an e-complaint application that is ready to be used by the Faculty of Engineering, Nurul Jadid University.

Keywords : Enhancement, Ability, E-Complaint, Service, Laboratory. 
Mei 2021

\section{PENDAHULUAN}

Keberadaan lembaga pendidikan tinggi berkembang layaknya industri jasa, perubahan bisa setiap saat sesuai dengan perkembangan teknologi informasi (Putri, Wibawa, \& Laksamana, 2017). Kebutuhan layanan mahasiswa dalam mendukung pendidikan tinggi sangat tergantung fasilitas pendukung dalam pembelajaran selama menempuh pendidikan di perguruan tinggi (Hermanto, Mustopa, \& Kuntoro, 2020). Pelayanan laboratorium merupakan salah satu unsur yang sangat penting dalam suasana akademik yang produktif (Tone, 2018). Penerapan aplikasi e-komplain untuk mencapai pelayanan yang prima terhadap mahasiswa merupakan faktor yang perlu diperhatikan untuk menjaga kelancaran dalam pengguanaan laboratorium (Siagian, 2018).

Peningkatan mutu pendidikan tinggi merupakan salah satu bagian mutu layanan akademik dan mutu pengajaran (Hidayat, Mulyana, \& Effendy, 2018). Kepuasan mahasiswa sebagai objek dari kegiatan akademik akan memperoleh layanan yang optimal (Andriani, 2012). Laboratorium Fakultas Teknik merupakan laboratorim yang ada di Universitas Nurul Jadid dengan pemanfaatkan khusus mahasiswa teknik dan bisa juga digunakan oleh mahasiswa lain diluar Fakultas Teknik yang akan menggunakan laboratorium komputer dengan beberpa aturan yang harus dipenuhi dan diluar jadwal praktikum mahasiswa Fakultas Teknik.

Dengan padatnya penggunaan laborarorium tentunya akan menambah peningkatan perhatian manajemen terhadap layanan penggunaan laboraotorim, pemakaian laboratorium untuk mahasiswa sesuai dengan roster yang dikeluarkan oleh prodi masing yang ada di Fakultas Teknik tentu ada pemakaian laboratorium ekstra diluar jadwal yang ditetapkan. Dalam menggunakan laboratorium harus sesuai Standar Operational System (SOP) yang terlah ditetapkan kepala laboratorium (W.F., T., \& N, 2017). Komplain merupakan salah satu bagian ada dalam aturan tersebut akan mendukung manajemen untuk menampung keluhan yang disampaikan oleh pengguna laboratorium. Keluhan selama ini masih bersifat call centre aduan dipandang kurang maksimal dan belum terwakilkan dengan kondisi riil di lapangan, maka perlu dibangun sebuah aplikasi e-komplain. Aplikasi e-komplain akan mengakomodir keluhan semua pengguna laboratorium mulai dari software, hardware dan keluhan pelayanan dari tenaga laboran. Aplikasi tersebut akan menjadi monitoring dan bahan evaluasi dari manajemen Fakultas Teknik terhadap pelayanan pendukung pendidikan yang menjadi hak dari mahasiswa Fakultas Teknik. Pengguna laboratorium dapat mengakses aplikasi e-komplain untuk keperluan antara lain (1) pemakaian laboratorium diluar jadwal perkuliahan yang telah ditetapkan oleh prodi masing-masing. (2) keluhan kerusakan hardware dan ketidak sesuaian software yang dibutuhkan oleh mahasiswa (3) keluhan fasilitas laboratorium yang tidak sesuai dengan Standar Operational System (SOP). 
E-ISSN: 2776-3331

Vol. 1, No. 1, pp.8o-85

Mei 2021

\section{METODE}

Metode dalam pengabdian ini menggunakan metode Longitudinal Method merupakan metode untuk menentukan dan mengukur data secara berulang untuk satu atau beberapa variable, pengulangan agar memberikan data valid dengan kondisi objek. Tujuan dari metode longitudinal adalah suatu upaya untuk mencari kebenaran tentang suatu masalah (Syafiih, 2020). Metode ini yang bertjuan untuk mengetahui perubahan sikap, perilaku ataupun pendapat sekelompok orang dari waktu ke waktu, adapun kerangka sebagaimna berikut :

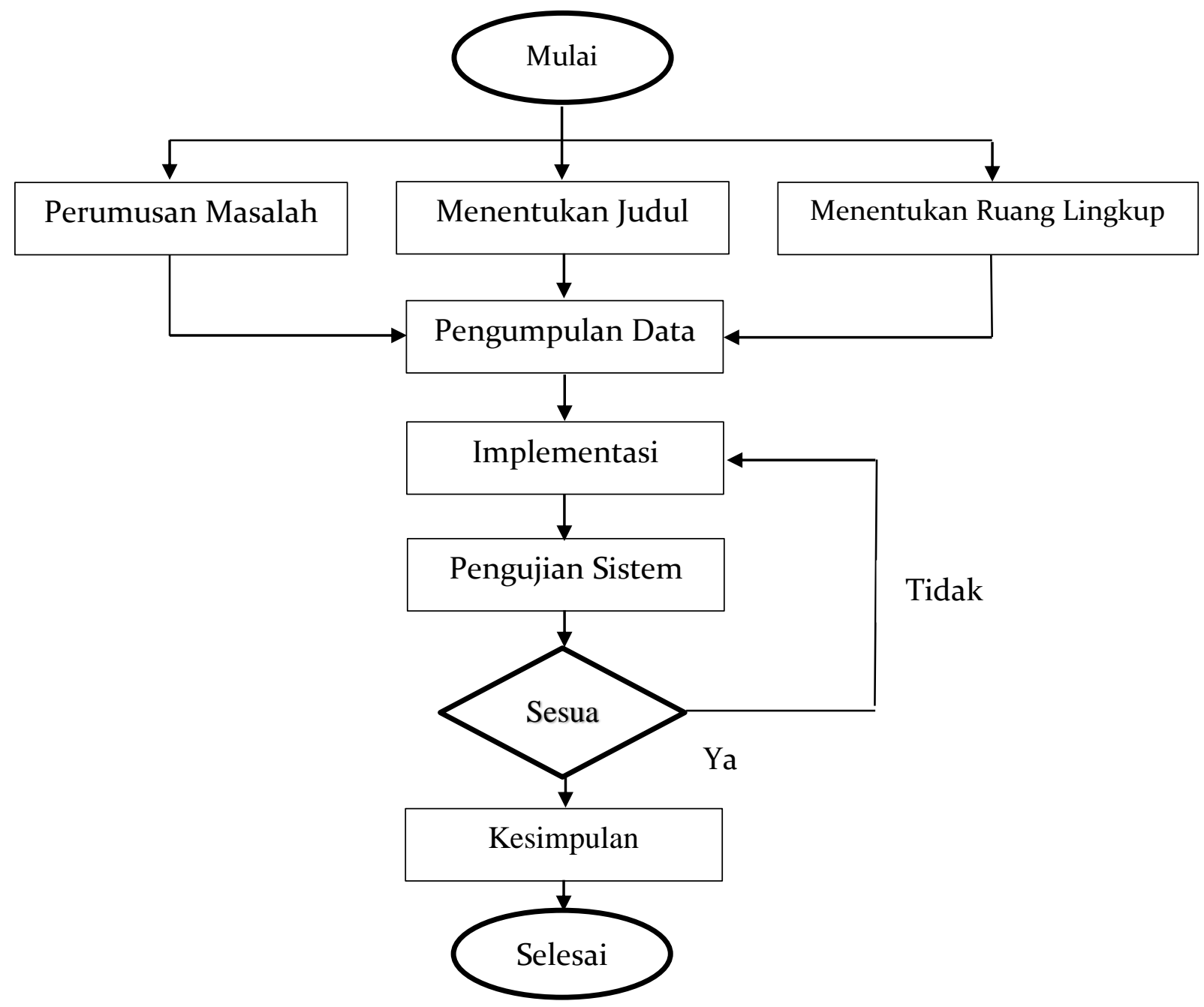

\section{Gambar 1. Bagan Metode}

Dalam tahapan ini setelah memulai akan merumuskan masalah yang adi di pelayanan manajemen laboratorium Fakultas Teknik Universitas Nurul Jadid, tahapan berikutnya adalah penentuan judul yang akan ditetapkan untuk pengabdian. Berdasarkan hasil wawancara dalam sebuah observasi sangat dibutuhkan aplikasi yang bisa menampung informasi penggunaan laboratorium serta keluhan dari pengguna (Andayani \& Syafiih, 2019), karena selama ini keluhan dari pemakaian laboratorium tidak tersistem dengan baik sehingga tindak lanjut dari keluhan kadang tidak ada solusi yang sesuai dengan harapan semua. Menentukan ruang lingkup pengabdian hanya di laboratorium Fakultas Teknik, selanjutnya pengumpulan data yang diperlukan 
terkait dengan topik yang ditetapkan. Implementasi adalah tahapan pembuatan aplikasi sesuai dari hasil pengumpulan data yang diperoleh. Aplikasi perlu adanya uji coba untuk menentukan kelayakan dan kesesuaian dengan kebutuhan, apabila hasil uji coba tidak sesuai maka perlu adanya perbaikan sampai benar-benar sesuai untuk menentukan kesimpulan bahwa aplikasi tersebut layak untuk mengatasi keluhan mahasiswa atau dosen yang menggunakan laboratorium.

\section{HASIL DAN PEMBAHASAN}

Untuk menyampaikan hasil dari sebuah pengabdian maka kita perlu menyampaikan pembahasan yang aka disampaikan. Dari hasil aplikasi yang berhasil kami ciptakan maka perlu adanya sosialisasi terhadap pengguna dari aplikasi tersebut, tahapan awal ialah mempresentasikan aplikasi didapan manajemen Fakultas Teknik tujuannya untuk mengetahui penggunaan aplikasi serta pemanfaatan bagi manajemen fakultas. Untuk tahapan berikutnya mengadakan pelatihan pengguanaan aplikasi ekomplain bagi manajemen laboratorium sebagaimana gambar dibawah :
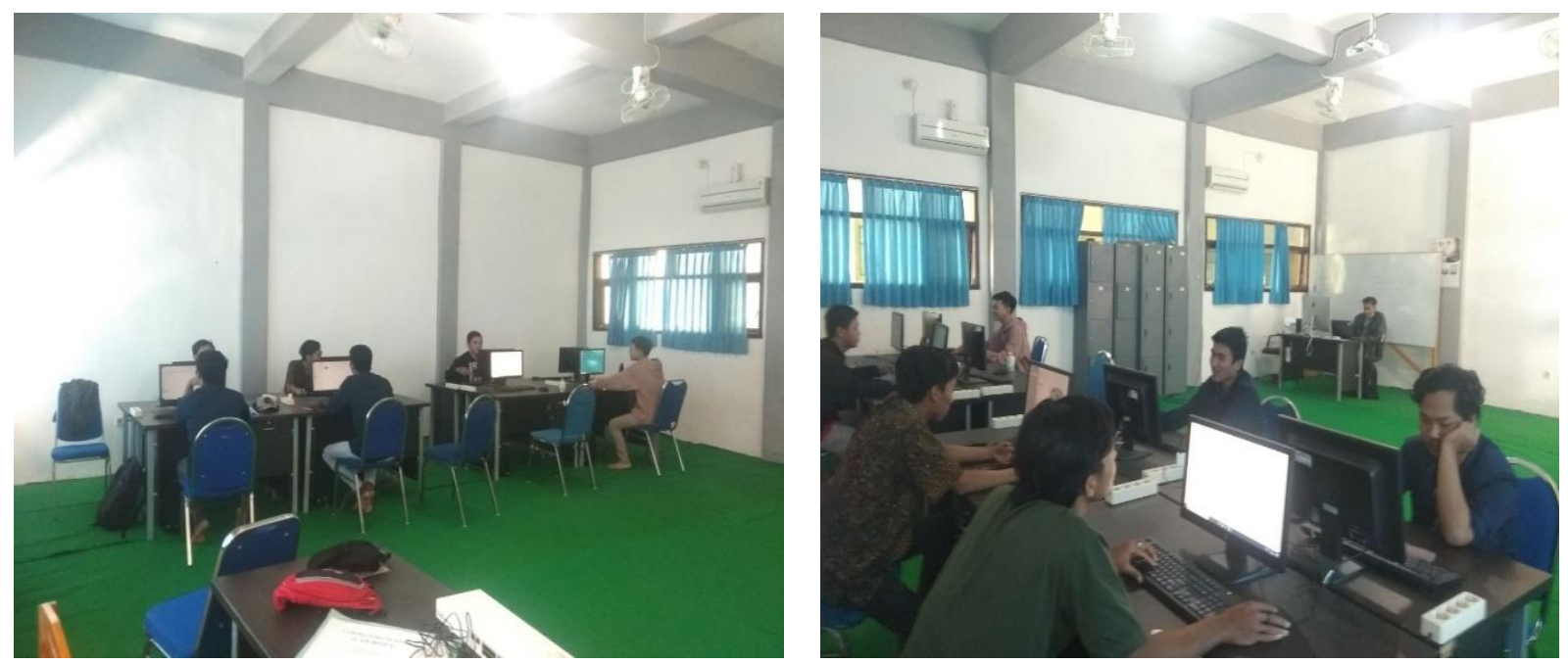

Gambar 2. Pelatihan Penggunaan Aplikasi E-Komplain

Dari pengabdian ini telah menghasilkan aplikasi e-komplain, serta telah melaksanakan pelatihan bagai manajemen laboratorium sebagai pengguna dari aplikasi tersebut. Aplikasi ini nantinya akan menjadikan solusi dari permasalahan selama ini yang menjadi titik dari semua persoalan di layanan laboratorim. Adapun hasil dari aplikasi tersebut sebagaimana gambar di bawah : 


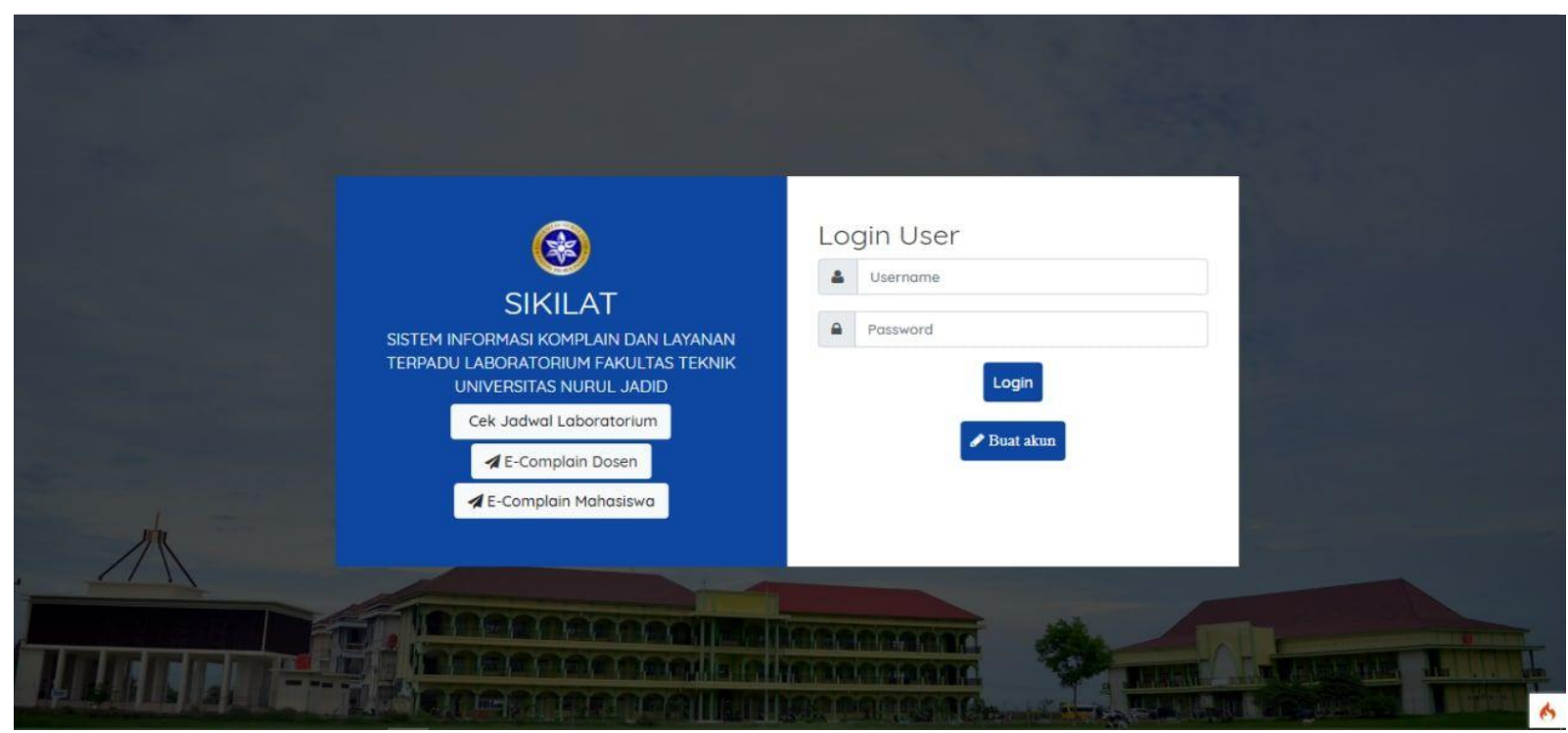

Gambar 3. Halaman Utama aplikas E-Komplain

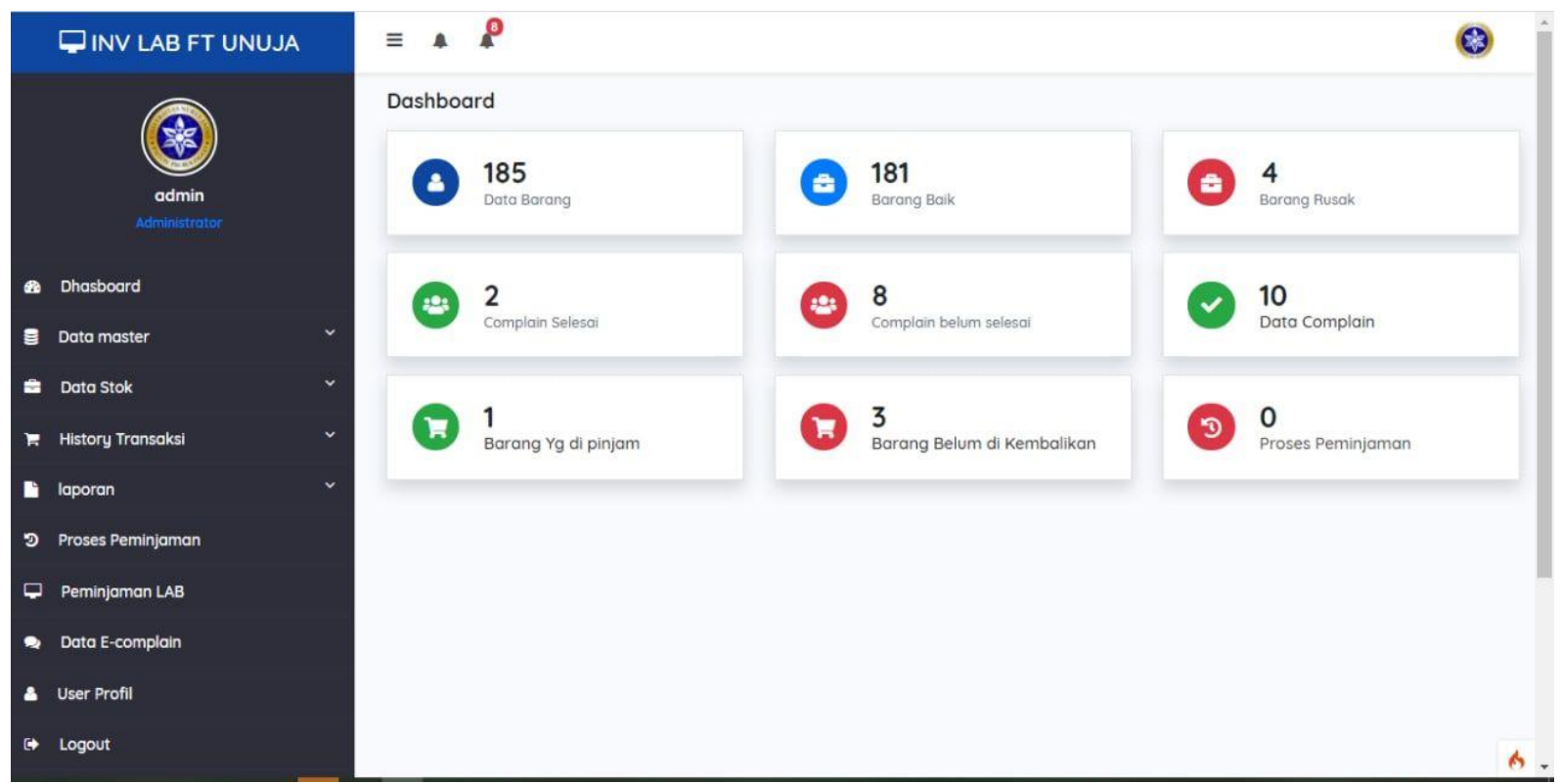

Gambar 4. Menu Utama aplikasi E-komplain

\section{KESIMPULAN}

Kegiatan pelatihan bagi manajemen laboratorium menjadi awal sebuah perubahan dari suatu sistem yang amburadul menjadi sistem yang efektif dan efisien. Hasil cipta dari aplikasi adalah salah solusi terbesar dari sebuah permasalahan selama ini yang dialami oleh manajemen Fakultas Teknik Universitas Nurul Jadid. Mahasiswa akan lebih kondusif menggunakan laboratorium karena semua, semua keluhan akan segera ada tindaklanjut dari manajemen untuk memberikan pelayanan yang terbaik. 
E-ISSN: $2776-3331$

Vol. 1, No. 1, pp.8o-85

Mei 2021

UCAPAN TERIMA KASIH

Ucapan terima kasih kami sampaikan kepada Dekan Fakultak Teknik Universitas Nurul Jadid atas kesempatan yang telah diberikan kepada kami untuk melakukan pengabdian sehingga kerjasama seperti ini akan berlangsung pada kesempatan lainnya. Terima kasih kepada Rektor Universitas Nurul Jadid atas atensi yang diberikan semoga menjadi pelajaran dan pengalaman bagi kami.

\section{REFERENSI}

Andayani, S. A., \& Syafiih, M. (2019). Penurunan Anka Kematian Ibu dan Anak Melalui Pemetaan Ibu Hami Kategori Kegawatan Berbasis GIS di Kabupaten Probolinggo. Jurnal Cyber-Techn, 1-8.

Andriani, D. E. (2012). Peningkatan Mutu Guru Berbasis Kebutuhan. Jurnal Manajemen Pendidikan, 395-402.

Hermanto, Mustopa, A., \& Kuntoro, A. Y. (2020). Algoritma Klasifikasi Naive Bayes dan Support Vector. Jurnal Ilmu Pengetahuan Dan Teknologi Komputer, 211-220.

Hidayat, L., Mulyana, \& Effendy. (2018). Membangun Kepuasan Mahasiswa Pengguna Laboratorium Komputer. JAS-PT Jurnal Analisis Sistem Pendidikan Tinggi Indonesia, 93-101.

Putri, R. O., Wibawa, B. M., \& Laksamana, T. (2017). Identifikasi Permasalahan Komplain pada E-Commerce Menggunakan Metode Fishbone. Jurnal Sains dan Seni ITS, 37-41.

Siagian, D. (2018). Proses Komunikasi Organisasi Pimpinan Dalam Penyelesaian Komplain Pelanggan (Studi Kasus Pada Perusahaan CV. Glory Victory di Kota Medan. Doctoral Dissertation), 9-16.

Syafiih, M. (2020). Pengembangan Aplikasi Pembelajaran Biologi pada Filum Arthophoda Dalam Kelas Insecta Augmented Reality Studi Kasus Dinas Pendidikan Kabupaten Probolinggo. Jurnal Cyber-Techn, 1-9.

Tone. (2018). Sistem Pengelolaan Manajemen Laboratorium Komputer Jurusan Sistem Informasi UIN Alauddin Makasar. Jurnal INSTEK (Informatika Sains dan Teknologi, 61-70.

W.F., S., T., W., \& N, A. (2017). Perancangan dan Evaluasi Usability Aplikasi Pengelolaan Laboratorium Komputer. Journal Of Information Systems Engineering and Buiness Intelligence, 101-106. 